\title{
Severity of parkinsonism associated with environmental manganese exposure
}

\author{
Brad A. Racette ${ }^{1,2^{*}}$, Gill Nelsonn ${ }^{2,3}$, Wendy W. Dlamini ${ }^{1}$, Pradeep Prathibha ${ }^{4}$, Jay R. Turner ${ }^{4}$, Mwiza Ushe ${ }^{1}$,
} Harvey Checkoway ${ }^{5}$, Lianne Sheppard ${ }^{6}$ and Susan Searles Nielsen ${ }^{1}$

\begin{abstract}
Background: Exposure to occupational manganese $(\mathrm{Mn})$ is associated with neurotoxic brain injury, manifesting primarily as parkinsonism. The association between environmental $\mathrm{Mn}$ exposure and parkinsonism is unclear. To characterize the association between environmental Mn exposure and parkinsonism, we performed populationbased sampling of residents older than 40 in Meyerton, South Africa $(N=621)$ in residential settlements adjacent to a large $\mathrm{Mn}$ smelter and in a comparable non-exposed settlement in Ethembalethu, South Africa $(\mathrm{N}=95)$ in 20162020.

Methods: A movement disorders specialist examined all participants using the Unified Parkinson Disease Rating Scale motor subsection part 3 (UPDRS3). Participants also completed an accelerometry-based kinematic test and a grooved pegboard test. We compared performance on the UPDRS3, grooved pegboard, and the accelerometrybased kinematic test between the settlements using linear regression, adjusting for covariates. We also measured airborne $\mathrm{PM}_{2.5}-\mathrm{Mn}$ in the study settlements.

Results: Mean $\mathrm{PM}_{2.5}$-Mn concentration at a long-term fixed site in Meyerton was $203 \mathrm{ng} / \mathrm{m}^{3}$ in 2016-2017 approximately double that measured at two other neighborhoods in Meyerton. The mean Mn concentration in Ethembalethu was 20 times lower than that of the long-term Meyerton site. UPDRS3 scores were $6.6(\mathrm{Cl} 5.2,7.9)$ points higher in Meyerton than Ethembalethu residents. Mean angular velocity for finger-tapping on the accelerometry-based kinematic test was slower in Meyerton than Ethembalethu residents [dominant hand 74.9 (Cl $48.7,101.2)$ and non-dominant hand 82.6 (Cl 55.2, 110.1) degrees/second slower]. Similarly, Meyerton residents took longer to complete the grooved pegboard, especially for the non-dominant hand (6.9, $\mathrm{Cl}-2.6,16.3 \mathrm{~s}$ longer).
\end{abstract}

Conclusions: Environmental airborne Mn exposures at levels substantially lower than current occupational exposure thresholds in the United States may be associated with clinical parkinsonism.

Keywords: Case control studies, Parkinson disease, Parkinsonism, Manganese

\footnotetext{
* Correspondence: racetteb@wustl.edu

'Department of Neurology, Washington University School of Medicine, 660

South Euclid Avenue, Campus Box 8111, 63110 St. Louis, Missouri, USA

${ }^{2} \mathrm{School}$ of Public Health, Faculty of Health Sciences, University of the

Witwatersrand, 7 York Road, 2193 Parktown, South Africa

Full list of author information is available at the end of the article
}

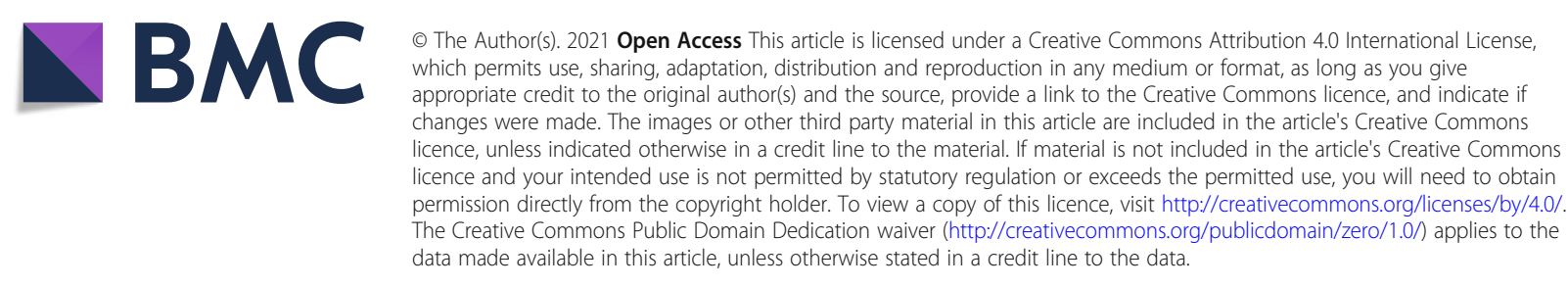




\section{Background}

Manganese (Mn) is an essential trace element [1] but also a neurotoxin at higher levels. Routes of entry are oral, respiratory, and, possibly, trans-olfactory. Mn that bypasses the liver is actively transported across the blood-brain barrier and appears to accumulate in the basal ganglia [2]. Oral Mn uptake is tightly regulated to maintain homeostatic Mn blood levels, so neurotoxicity in adults appears to be related primarily to inhaled $\mathrm{Mn}$ [3]. Millions of people worldwide are exposed to airborne environmental $\mathrm{Mn}$ due to fossil fuel combustion, air erosion of Mn-laden soils proximate to mining operations, and industrial stack emissions from high temperature industrial processes, such as smelting and steelmaking. Numerous studies demonstrate an association between occupational $\mathrm{Mn}$ exposure and motor dysfunction [4-8]. There is also evidence of Mn-related motor dysfunction [9-17], in relation to environmental Mn exposure in adults, but fewer studies have found clinically relevant motor health effects $[12,18]$. We have previously shown that Mn-exposed workers have Mndose-dependent parkinsonism [7] and dopaminergic dysfunction [19-21], at estimated mean airborne Mn concentrations ranging from 0.0175 to $0.14 \mathrm{mg} / \mathrm{m}^{3}$ over the course of a work shift. This and other studies [8, 22] suggest that there are adverse neurologic health effects from $\mathrm{Mn}$ exposures below the American Conference of Governmental Industrial Hygienists (ACGIH) threshold limit value for $\mathrm{Mn}$ of $0.1 \mathrm{mg} / \mathrm{m}^{3}$ [23]. The current United States (U.S.) Environmental Protection Agency (EPA) lowest observed adverse effect level (LOAEL) of $\mathrm{Mn}$ is $0.05 \mathrm{mg} / \mathrm{m}^{3}$, and was derived from findings from an occupational study [24]. We sought to examine whether we could detect motor health effects from ambient industrial Mn exposure in South Africa. We hypothesized that individuals with relatively high $\mathrm{Mn}$ environmental inhalational exposures would have poorer scores on clinically relevant measures of parkinsonism than those with lower exposures.

\section{Methods}

\section{Participants}

All participants lived in one of two communities in Gauteng province, South Africa at the time of enrollment, between 2016 and 2020.Participants in the Mn-exposed community, Meyerton, lived in one of three settlements (Old Sicelo, New Sicelo, or Noldick). This community is located in the Midvaal municipality, within $5 \mathrm{~km}$ of one of the world's largest Mn smelters, which has been in operation since 1951. Participants from the reference community lived in Ethembalethu, a settlement located approximately $70 \mathrm{~km}$ northwest of Meyerton, in the Mogale City municipality, with no nearby Mn smelting or mining operations. We chose Ethembalethu as the reference settlement due to its location in a non-industrial area, outside of Johannesburg, but otherwise largely similar sociodemographics (Table 1). Most notably, the selected Meyerton-based and Ethembalethu settlements are government-subsidized housing communities, so residents must meet the same income criteria to be allowed to live in these settlements.

Our research personnel recruited participants by visiting a preselected, population-based sample of homes in each settlement to attempt to recruit adults who met all inclusion criteria, as detailed below. For two of the three Meyerton-based settlements (New Sicelo and Noldick), we preselected every other residence using a municipality map. Research personnel attempted to recruit eligible adults in each residence to participate in the study. If no one was home, or if there were no eligible adults in the residence, the research personnel attempted to recruit the residence to the left of the preselected home. If no one was home or eligible in that residence, they proceeded to the next preselected home on the map. Because there were fewer residences in Old Sicelo than in the other two areas, research personnel attempted to recruit participants from every residence in that settlement. The reference community, Ethembalethu, was smaller than the Meyerton-based settlements, so we attempted to recruit every adult resident who met the study criteria, using the same door-to-door approach.

Inclusion criteria included current residence in the selected Meyerton-based settlements or Ethembalethu, age $\geq 40$, and ability to provide informed consent. After initial recruitment based upon these inclusion criteria, and completion of grooved pegboard (GP) testing, accelerometry-based kinematic testing, and the study questionnaire in the home, participants were asked to come for a second visit ("phase 2") to a local community center to be examined by a neurologist at a later time.After this clinical assessment phase 2 visit, enrolled participants were then excluded if they had neurologic comorbidities that made testing unreliable or were using a dopamine receptor blocking medication. Otherwise, we did not select participants with regard to any health outcomes or occupational exposures, and generally, participants only had non-occupational exposure to Mn.

\section{Assessment of UPDRS3 score and subscores}

One movement disorder specialist (B.A.R.) examined all participants for Parkinson disease (PD) and, more generally, signs of parkinsonism, using the Unified Parkinson Disease Rating Scale motor subsection part 3 (UPDRS3) [25]. The complete examination occurred while blinded to results on the GP test, accelerometry-based kinematic testing, and cumulative Mn exposure, i.e., current residence location within the respective community, past residential histories, and occupational histories. In 
addition to the UPDRS3 total score, we combined selected UPDRS3 subscores [7], as secondary outcomes, to determine if environmental Mn exposure was associated with specific clinical signs. In order to ensure that participants could be included even when a limb was severely injured or missing, or had a medical condition that precluded the pull test to assess balance, we imputed one or more missing subscores, when possible, using other subscores as predictors in linear regression models based on all participants with complete UPDRS3 subscores.

\section{Grooved pegboard and kinematic testing}

Participants completed selected motor tasks, as additional secondary outcomes, in their home at the time of recruitment. These included two tasks that assess fine motor function: the GP test and an accelerometry-based kinematic test (hereafter "kinematic test") that replicated the finger-tapping task from the UPDRS3 exam. For GP testing, we used a standard GP device (Lafayette Instrument Company, Lafayette, Indiana) and followed published testing procedures [26]. We recorded the time to place the 25 pegs for each hand up to $300 \mathrm{~s}$. Trained research personnel administered the kinematic test by placing a wireless motion sensor (Kinesia $^{\text {Tw}}$, Great Lakes NeuroTechnologies, Independence, Ohio) [27-31] on the top of the participant's index finger. The Kinesia Motion Sensory device is comprised of a triaxial accelerometer and triaxial gyroscope, allowing the measurement of acceleration (linear) and velocity (angular), respectively, along all three axes $(x, y$, and $z)$ at $64 \mathrm{~Hz}$. We recorded the digitized signals on a computer tablet, installed with motion capture software (Great Lakes NeuroTechnologies, Independence, Ohio). Participants were asked to complete three 12-second trials for each hand for a fingertapping task.Each participant tapped his/her index finger and thumb together, while keeping the other fingers stable and the elbow extended.Participants were instructed to perform the finger-tapping task with as large an amplitude and as fast as possible. We then processed the kinematic data using code we developed in Stata version MP 14.2 (StataCorp, College Station, Texas) [32] and validated this Stata processed data against manually processed data (Spearman's $\rho>0.99$ ). We used the mean angular velocity in degrees/second, hereafter referred to as mean velocity, across all three trials for the respective hand (dominant or non-dominant). We used self-reported handedness to classify the motor tasks as dominant or non-dominant. Even after age-adjustment, both motor tasks in each hand were strongly associated with the UPDRS3 (all $P$ values $<0.001$ ).

\section{Assessment of $\mathrm{mn}$ exposure}

We used community (Meyerton, Ethembalethu) as an indicator of $\mathrm{Mn}$ exposure status. To verify and quantify potential differences in airborne $\mathrm{Mn}$ exposure, we measured ambient Mn concentrations in both communities. We collected fine particulate matter $\left(\mathrm{PM}_{2.5}\right.$, particles with aerodynamic diameter $\leq 2.5 \mu \mathrm{m})$ on Teflon ${ }^{\circ}$ filters (Measurement Technology Corporation, Minneapolis, $\mathrm{MN}$ ) using air samplers with $\mathrm{PM}_{2.5}$ inlets (Model PQ100, Mesa Labs, Butler, NJ) operating continuously for two- to three-days for each sample. Long-term routine air sampling at a fixed site in the Meyerton settlement of Noldick began in October 2015 and was completed in May 2018. For the two-year period 2016$2017,47 \%$ of all hours were represented ( $n=158$ filters). We assessed spatial variability across the Meyertonbased settlements by collecting samples concurrently in Old Sicelo and Noldick (October 2018-February 2019, $n=37$ filters), and New Sicelo and Noldick (September 2017-May 2018 and October 2018, n = 55 filters). We conducted air sampling in Ethembalethu in JanuaryOctober 2020 ( $n=68$ filters) with no concurrent sampling in Meyerton. Filter membranes were digested using a MARS $6^{\mathrm{TM}}$ microwave digestion system (CEM, Matthews, NC) using a validated protocol [33]. We filtered these digestates through $0.45 \mu \mathrm{m}$ (pore size) nylon syringe filters (VWR, Radnor, PA) and diluted them with deionized water $(\geq 18.2 \mathrm{M} \Omega / \mathrm{cm}$ resistivity, MilliQ Water Purification System, EMD Millipore, Burlington, MA). Mn was quantified using an inductively coupled plasmamass spectrometer (NexION ${ }^{\circledR} 2000$, Perkin-Elmer, Norwalk, CT). The limit of detection for Mn was $0.056 \mathrm{ng} /$ $\mathrm{m}^{3}$ in $\mathrm{PM}_{2.5}$ [34]. Instrument performance was validated using NIST 1648a Urban Particulate Matter (Sigma-Aldrich, St. Louis, MO), yielding Mn recovery of $96.9 \pm$ $8.4 \%$.

\section{Statistical analysis}

We performed all statistical analyses using Stata version MP 14.2 [32]. We used linear regression with each of the motor outcomes as continuous dependent variables. $\mathrm{Mn}$ exposure, as assessed by whether the residence was in the exposed (Meyerton) or non-exposed (Ethembalethu) community, was the independent variable of primary interest. Our primary motor outcome was the total UPDRS3 score. Given the known strong, positive association between age and both UPDRS3 scores [7] and other motor outcomes, we adjusted a priori for age in all models. We retained age as a continuous variable and adjusted for age using natural cubic splines with five knots, following Harrell's placement method, i.e., knots equally spaced at the 5th, 27.5th, 50th, 72.5th and 95th percentiles [35]. In practice, five knots are considered a good choice to model the overall shape of a parameter for sample sizes $\geq 100[35,36]$. We also examined the effects of adjustment for sex, cigarette smoking, and alcohol use, with the latter two as trichotomous variables (never, former, current use). These demographic 
Table 1 Characteristics of residents and households, by municipality $^{a}$

\begin{tabular}{|c|c|c|}
\hline & $\begin{array}{l}\text { Midvaal (includes Meyerton } \\
\text { settlements Noldick, Old Sicelo, New } \\
\text { Sicelo) }\end{array}$ & $\begin{array}{l}\text { Mogale City } \\
\text { (includes } \\
\text { Ethembalethu) }\end{array}$ \\
\hline \multicolumn{3}{|l|}{ Households } \\
\hline $\begin{array}{l}\text { Formal } \\
\text { dwelling, \% }\end{array}$ & 80.2 & 73.5 \\
\hline $\begin{array}{l}\text { Female-headed, } \\
\%\end{array}$ & 26.3 & 31.2 \\
\hline Owned, ${ }^{\text {b }} \%$ & 42.6 & 39.0 \\
\hline \multicolumn{3}{|l|}{ Utilities, \% } \\
\hline $\begin{array}{l}\text { Piped water } \\
\text { inside dwelling }\end{array}$ & 64.9 & 54.8 \\
\hline $\begin{array}{l}\text { Flush toilet/ } \\
\text { sewer }\end{array}$ & 58.0 & 78.2 \\
\hline $\begin{array}{l}\text { Electricity for } \\
\text { lighting }\end{array}$ & 79.3 & 85.9 \\
\hline $\begin{array}{l}\text { Weekly removal } \\
\text { of refuse }\end{array}$ & 82.1 & 79.7 \\
\hline \multicolumn{3}{|l|}{$\underline{\text { Residents }}$} \\
\hline $\begin{array}{l}\text { Total } \\
\text { population, N }\end{array}$ & 95,301 & 362,422 \\
\hline $\begin{array}{l}\text { Population } \\
\text { density, persons/ } \\
\mathrm{km}^{2}\end{array}$ & 55 & 270 \\
\hline \multicolumn{3}{|l|}{ Sex, \% } \\
\hline Female & 48.4 & 49.0 \\
\hline Male & 51.6 & 51.0 \\
\hline \multicolumn{3}{|l|}{ Race, \% } \\
\hline Black & 58.4 & 75.6 \\
\hline White & 38.7 & 21.0 \\
\hline Other & 2.9 & 3.5 \\
\hline \multicolumn{3}{|l|}{ Age, years, $\%$} \\
\hline $0-14$ & 23.2 & 23.7 \\
\hline $15-64$ & 70.5 & 71.7 \\
\hline$\geq 65$ & 6.3 & 4.6 \\
\hline $\begin{array}{l}\text { Dependency } \\
\text { ratio }^{c}\end{array}$ & 41.9 & 39.4 \\
\hline \multicolumn{3}{|c|}{ Education (age $\geq 20$ years), \% } \\
\hline No schooling & 5.2 & 4.7 \\
\hline $\begin{array}{l}\text { Primary/ } \\
\text { secondary }\end{array}$ & 47.5 & 48.6 \\
\hline $\begin{array}{l}\text { Matric (high } \\
\text { school) }\end{array}$ & 32.1 & 32.6 \\
\hline $\begin{array}{l}\text { Higher } \\
\text { education }\end{array}$ & 15.2 & 14.1 \\
\hline \multicolumn{3}{|l|}{ Unemployed, \% } \\
\hline Overall & 18.8 & 24.6 \\
\hline Youth & 25.4 & 32.3 \\
\hline No income, \% & 14.5 & 15.5 \\
\hline
\end{tabular}

a Statistics South Africa, 2011 ()

b Owned includes "paying off" a loan for purchase of the home

c All ratios presented are multiplied by 100 . The dependency ratio is the number of residents' age $0-14$ or $\geq 65$, divided by residents' age 15-64 variables are associated with PD [37-39] and therefore might also be associated with UPDRS3 scores and other motor outcomes. We conducted three additional sensitivity analyses. First, we excluded participants with imputed UPDRS3 subscores to assess the stability of the results.Second, because kinematic test data were not available for some participants, we repeated the kinematic analysis while applying inverse probability weighting to give greater weight to participants with characteristics associated with missing kinematic data (as estimated by a logistic regression model that predicted missingness of kinematic data).Finally, we excluded participants with any current or previous occupational Mn exposure.In addition, through exploratory analyses we investigated whether restriction of Meyerton participants to those who had lived in the same home in Meyerton since before 2008 (when Mn production at the smelter decreased due to a recession) revealed stronger associations for the motor outcomes. For all analyses, we considered a two-sided $\mathrm{P}$ value of 0.05 as statistically significant, evidenced by the exclusion of zero from the $95 \% \mathrm{CI}$ for the $\beta$ coefficient, i.e., adjusted mean difference between Meyerton and Ethembalethu.

\section{Results}

Out of the 666 homes we visited in Meyerton, 462 $(69.4 \%)$ had at least one eligible adult who agreed to participate; and out of the 108 homes we visited in Ethembalethu, 79 (73.1\%) had at least one eligible adult who agreed to participate.Initially, we recruited 832 eligible participants (732 in Meyerton, 100 in Ethembalethu) (Fig. 1). The median time between the first and second visits in Meyerton and Ethembalethu was 49 and 3 days, respectively. Of those who were enrolled at the first visit, $629(85.9 \%)$ and 96 (96.0\%), respectively, attended the phase 2 clinical assessment visit in Meyerton and Ethembalethu. After excluding some participants for co-morbidities, we retained 621 (98.7\%) and 95 (99.0\%) eligible participants in each of the communities, respectively, who had complete UPDRS3 scores, following imputation of selected subscores for 17 individuals.We obtained GP testing data from both hands for $605(97.4 \%)$ and 93 (97.9\%) participants, respectively, and we obtained kinematic test data from both hands for 346 (55.7\%) Meyerton participants and $91(95.8 \%)$ Ethembalethu participants.Most participants in both communities were Black $(98.9 \%$ in Meyerton and $97.9 \%$ in Ethembalethu). Other demographic characteristics of the participants and their communities are in Tables 1 and 2, respectively.

In Meyerton, the two-year (2016-2017) mean $\mathrm{PM}_{2.5^{-}}$ $\mathrm{Mn}$ concentration from the long-term particulate matter air sampling in Noldick was $203 \mathrm{ng} / \mathrm{m}^{3}$. Based on the 


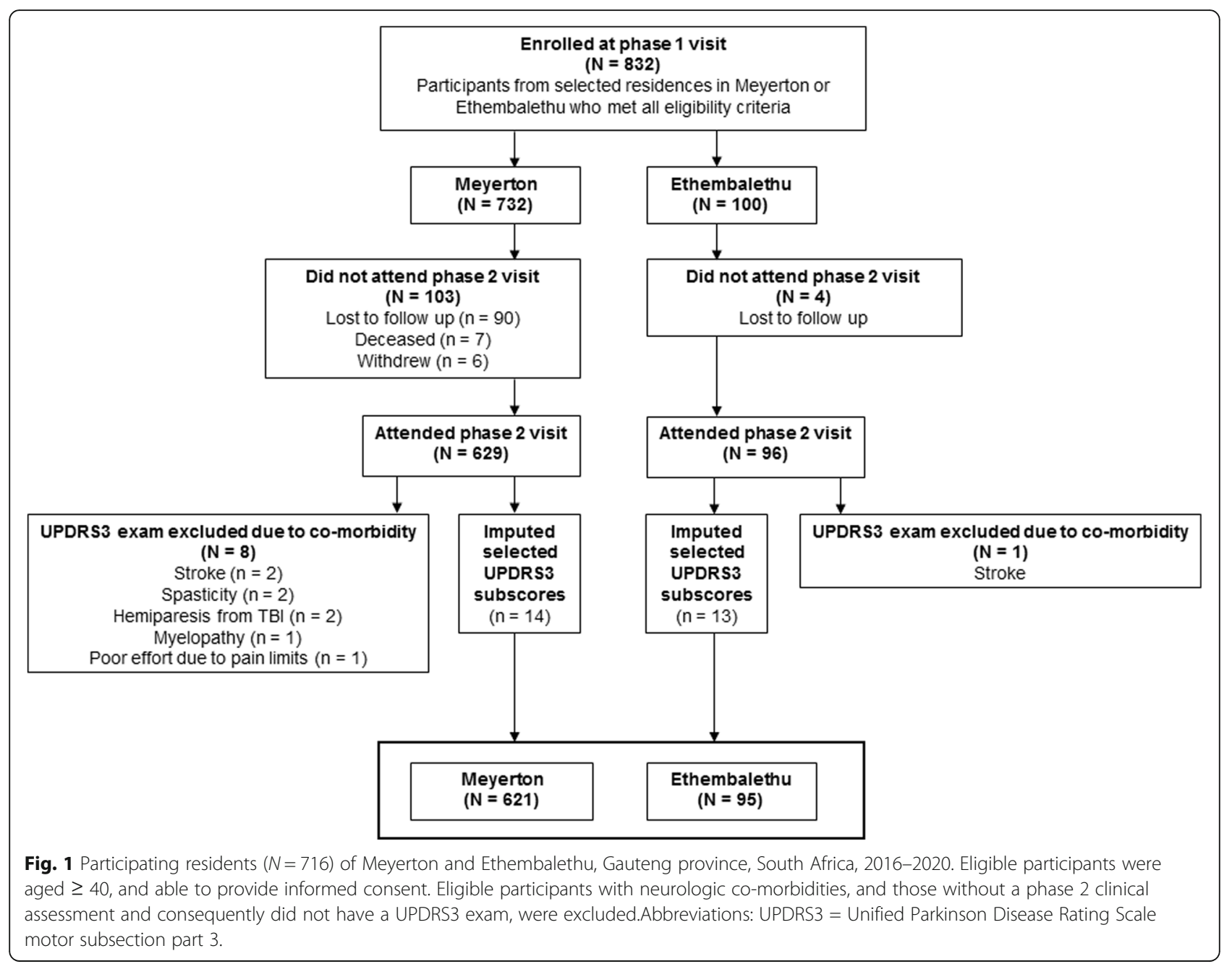

concurrent sampling in Noldick and the other two settlements in Meyerton, the mean was approximately twice that for both Old Sicelo and New Sicelo; the $\mathrm{PM}_{2.5}-\mathrm{Mn}$ ratio of means were 0.45 at Old Sicelo and 0.65 at New Sicelo, compared to Noldick. The $\mathrm{PM}_{2.5-}$ Mn mean concentration in Ethembalethu (year 2020) was $10 \mathrm{ng} / \mathrm{m}^{3}$, i.e., $\sim 20$ times lower than the concentrations in Noldick.

The mean UPDRS3 score was higher in Meyerton than Ethembalethu residents (Fig. 2), with mean UPDRS3 scores of 9.3 (SD 7.2) in Meyerton and 3.7 (SD 4.1) in Ethembalethu (Table 3). After accounting for the slightly younger mean age of residents from Meyerton compared to Ethembalethu, residents of Meyerton had a UPDRS3 score 6.6 (CI 5.2, 7.9) points higher than residents of Ethembalethu, on average (Table 4). This difference was driven by higher subscores for upper limb bradykinesia and rigidity and lower limb bradykinesia and rigidity, with each individual subscore in these categories contributing approximately 0.5 points, on average, for Meyerton vs. Ethembalethu residents (Table 4). The association between community and total UPDRS3 score was not changed materially with adjustment for factors in addition to age, with only $4.5 \%$ attenuation after adjustment for sex, smoking, and alcohol. Results were consistent when excluding 17 participants with missing UPDRS3 subscores and, separately, 14 participants with any history of occupational Mn exposure. The association between community and UPDRS3 did not differ according to age, sex, smoking, or alcohol use (all interaction $\mathrm{P}$ values $>0.05$ ). In addition to the differences in UPDRS3 score by community, Meyerton residents had a slower mean velocity on the kinematic test than Ethembalethu residents [74.9 (CI 48.7, 101.2) degrees/second slower for the dominant hand, and 82.6 (CI 55.2, 110.1) degrees/second slower for the non-dominant hand] (Tables 4 and 5). This association was attenuated somewhat, but clearly remained, when we applied inverse probability weighting to address missingness of kinematic test data. Specifically, Meyerton residents were 58.7 (CI 27.6, 89.7) and 65.7 (CI 32.4, 99.1) degrees/second slower in the dominant and non-dominant hand, respectively, 
Table 2 Characteristics of participants, overall and by community, Gauteng province, South Africa, 2016-2020

\begin{tabular}{|c|c|c|c|}
\hline & $\begin{array}{l}\text { All participants } \\
N=716\end{array}$ & $\begin{array}{l}\text { Mn smelter community (Meyerton) } \\
N=621\end{array}$ & $\begin{array}{l}\text { Reference community } \\
\text { (Ethembalethu) } \\
N=95\end{array}$ \\
\hline & n (\%) & n (\%) & n (\%) \\
\hline \multicolumn{4}{|l|}{ Sex } \\
\hline Female & $405(56.6)$ & $339(54.6)$ & $66(69.5)$ \\
\hline Male & $311(43.4)$ & $282(45.4)$ & $29(30.5)$ \\
\hline \multicolumn{4}{|l|}{ Race $^{a}$} \\
\hline Black & $706(98.7)$ & 614 (98.9) & $92(97.9)$ \\
\hline Other & $9(1.3)$ & $7(1.1)$ & $2(2.1)$ \\
\hline \multicolumn{4}{|l|}{ Language $^{\mathrm{b}}$} \\
\hline Sesotho & $366(51.3)$ & $352(57.0)$ & $14(14.7)$ \\
\hline IsiXhosa & $107(15.0)$ & $99(16.0)$ & $8(8.4)$ \\
\hline IsiZulu & $107(15.0)$ & $91(14.7)$ & $16(16.8)$ \\
\hline Setswana & $44(6.2)$ & $14(2.3)$ & $30(31.6)$ \\
\hline Sepedi & $25(3.5)$ & $19(3.1)$ & $6(6.3)$ \\
\hline Other & $64(9.0)$ & $43(7.0)$ & $21(22.1)$ \\
\hline \multicolumn{4}{|l|}{ Education ${ }^{c}$} \\
\hline None/non-formal schooling & $100(14.6)$ & $92(15.5)$ & $8(8.9)$ \\
\hline Primary & $252(36.8)$ & $214(36.0)$ & $38(42.2)$ \\
\hline Secondary & $226(33.0)$ & $198(33.3)$ & $28(31.1)$ \\
\hline Matric or higher & 107 (15.6) & $91(15.3)$ & $16(17.8)$ \\
\hline Unemployed $^{d}$ & $354(50.6)$ & $317(52.3)$ & 37 (39.4) \\
\hline \multicolumn{4}{|l|}{ Smoking cigarettes ${ }^{\mathrm{e}}$} \\
\hline Never & $493(69.3)$ & $413(66.6)$ & $80(87.9)$ \\
\hline Former & $57(8.0)$ & $56(9.0)$ & $1(1.1)$ \\
\hline Current & $161(22.6)$ & $151(24.4)$ & $10(11.0)$ \\
\hline \multicolumn{4}{|l|}{ Alcohol use } \\
\hline Never & $367(51.3)$ & $301(48.5)$ & $66(69.5)$ \\
\hline Former & $113(15.8)$ & $101(16.3)$ & $12(12.6)$ \\
\hline Current & $236(33.0)$ & $219(35.3)$ & $17(17.9)$ \\
\hline Ever Mn occupational exposure & $14(2.0)$ & $14(2.3)$ & $0(0.0)$ \\
\hline \multirow[t]{2}{*}{ Current Mn occupational exposure } & $2(0.3)$ & $2(0.3)$ & $0(0.0)$ \\
\hline & Mean (SD) & Mean (SD) & Mean (SD) \\
\hline Age, years & $51.8(9.2)$ & $51.3(9.2)$ & $55.3(8.7)$ \\
\hline Minimum & 40 & 40 & 40 \\
\hline Median & 50 & 49 & 55 \\
\hline Maximum & 97 & 97 & 84 \\
\hline
\end{tabular}

Abbreviations: $M n$ manganese

a Percent excludes 1 participant from Ethembalethu with missing data. Other is White or of mixed race.

${ }^{b}$ Percent excludes 3 participants from Meyerton with missing data. Other languages are Xitsonga, Afrikaans, SiSwati, Tshivenda, and English.

c Percent excludes 31 participants with missing data ( 5 from Ethembalethu, and 26 from Meyerton); where primary is grades $1-7$, secondary is grades $8-11$, and matric is grade 12

d Percent excludes 16 participants with missing data ( 1 from Ethembalethu, and 15 from Meyerton).

e Percent excludes 5 participants with missing data (4 from Ethembalethu, and 1 from Meyerton).

compared to Ethembalethu residents. Similarly, there was a suggestion that Meyerton residents took longer to complete the GP test, for the non-dominant hand (6.9,
CI -2.6, 16.3 s longer). As with the UPDRS3 scores, results for the kinematic test and GP test were not materially changed by adjusting for additional covariates 


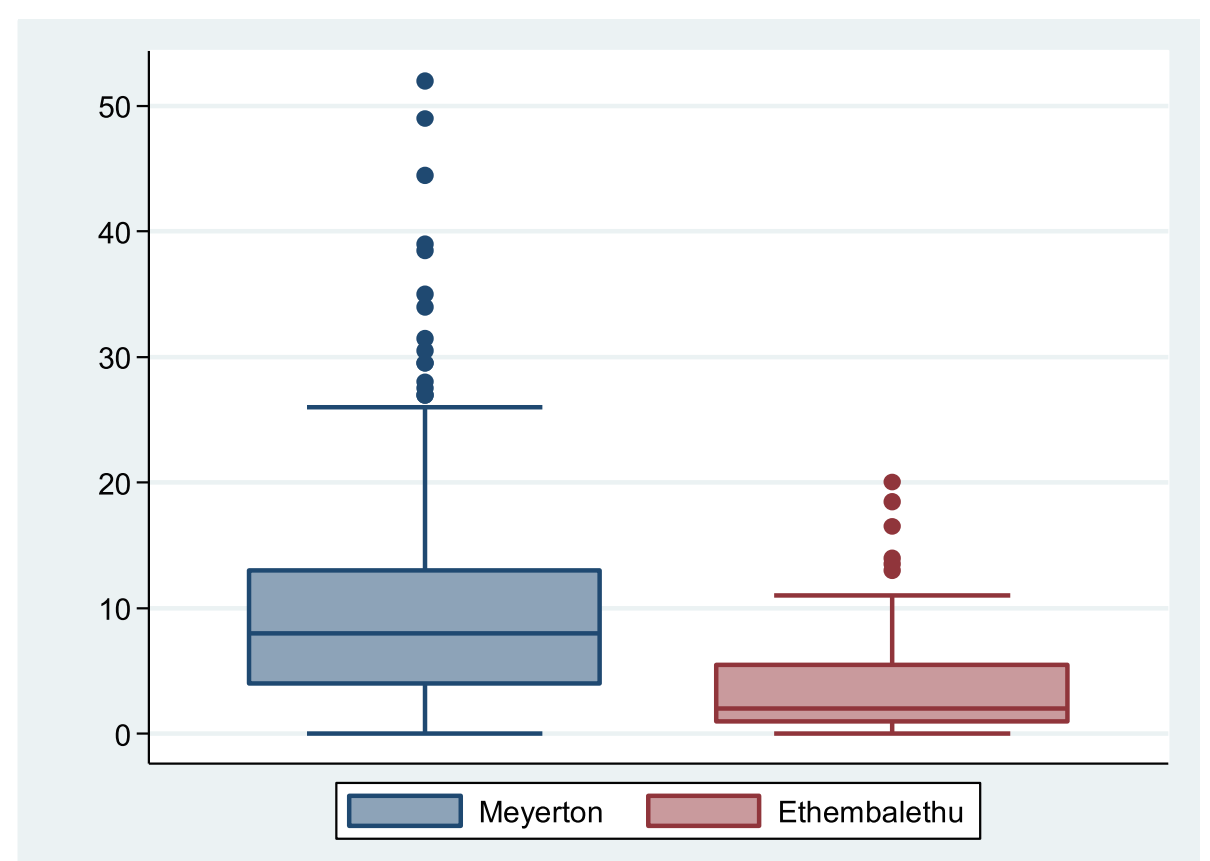

Fig. 2 Title: Box and whisker plot of UPDRS3 scores by community, Gauteng province, South Africa, 2016-2020. Figure demonstrates median, interquartile range, and overall UPDRS3 score range, including outliers, and shows greater severity of parkinsonism in the Mn smelter community of Meyerton ( $N=621$ ) as compared to the reference community of Ethembalethu $(N=95)$, Gauteng province, South Africa, 2016-2020. Abbreviations: Mn = manganese; UPDRS3 = Unified Parkinson Disease Rating Scale motor subsection part 3.

beyond age. Associations between community and each of the motor outcomes were not markedly different when we restricted the Meyerton residents to those who had lived in their homes since before 2008.

Five $(0.8 \%)$ participants from Meyerton and no participants from Ethembalethu had PD (Fisher's exact two-sided $P$ value $=1.00$, Fisher's exact one-sided $P$ value $=0.49$ ).

\section{Discussion}

This study provides evidence of an association between environmental $\mathrm{Mn}$ exposure and parkinsonian motor dysfunction. We chose a clinically relevant primary motor assessment of parkinsonism, the UPDRS3, which we previously demonstrated to be associated with PDspecific quality of life in language-adapted questionnaires in this population [40]. Interestingly, the mean UPDRS3 in the Meyerton community was similar to that reported in several occupationally exposed Mn populations [7, 8, 41]. This is notable because these contemporaneous worker populations experience estimated 8-hour timeweighted mean Mn exposures of 0.0175-0.23 $\pm 0.18 \mathrm{mg} /$ $\mathrm{m}^{3}[7,8,41]$, whereas ambient $\mathrm{Mn}$ concentration levels in our environmentally exposed population appeared to be substantially lower $\left(0.00075-0.0026 \mathrm{mg} / \mathrm{m}^{3}\right)$, at least during the study period. The longer time that Meyerton vs. Ethembalethu residents took to complete the GP test, and the slower finger-tapping on the accelerometry- based kinematic test, provide objective confirmation of the primary UPDRS3 results. Strengths of our study include a rigorous population-based sampling approach in the two similar communities and the use of standardized and clinically relevant motor outcomes. Our large study, with expert neurological assessments and measurement of airborne $\mathrm{Mn}$, provides evidence of an association between parkinsonism and environmental Mn exposure.

The neurologic health effects we observed in our Mnexposed community during the monitoring period occurred in the setting of two-year (2016-2017) average ambient $\mathrm{PM}_{2.5}-\mathrm{Mn}$ up to $215 \mathrm{ng} / \mathrm{m}^{3}$, with evidence that ambient concentrations were approximately half this value in the other two settlements from which we recruited participants in the exposed community. These ambient levels of Mn contrast with the U.S. EPA LOAEL of $0.05 \mathrm{mg} / \mathrm{m}^{3}\left(50,000 \mathrm{ng} / \mathrm{m}^{3}\right)$ and indicate there may be neurologic health effects associated with exposures substantially lower than the LOAEL for $\mathrm{PM}_{2.5}-\mathrm{Mn}$. One important caveat is that we measured $\mathrm{PM}_{2.5}-\mathrm{Mn}$ in Meyerton from 2015 to 2019 and Mn production at the smelter then was lower than it was before the 2008 recession. As a result, we may be underestimating the air concentrations to which our Meyerton participants were exposed in earlier years. Nevertheless, even Mn exposure an order of magnitude greater than our measured $\mathrm{PM}_{2.5}-\mathrm{Mn}$ levels still represents an exposure level far 
Table 3 UPDRS3 motor outcomes, overall and by community, Gauteng province, South Africa, 2016-2020

\begin{tabular}{|c|c|c|c|}
\hline & $\begin{array}{l}\text { All participants } \\
N=716\end{array}$ & $\begin{array}{l}\text { Mn smelter community (Meyerton) } \\
N=621\end{array}$ & $\begin{array}{l}\text { Reference community } \\
\text { (Ethembalethu) } \\
N=95\end{array}$ \\
\hline & n (\%) & n (\%) & n (\%) \\
\hline \multirow[t]{2}{*}{ Total UPDRS3 score $\geq 15^{a}$} & $123(17.2 \%)$ & $120(19.3 \%)$ & $3(3.2 \%)$ \\
\hline & Mean (SD) & Mean (SD) & Mean (SD) \\
\hline \multicolumn{4}{|l|}{$\underline{\mathrm{UPDRS}}^{\mathrm{a}}$} \\
\hline Total score & $8.5(7.1)$ & $9.3(7.2)$ & $3.7(4.1)$ \\
\hline Minimum & 0 & 0 & 0 \\
\hline Median & 7 & 8 & 2 \\
\hline Maximum & 52 & 52 & 20 \\
\hline Upper limb bradykinesia ${ }^{\mathrm{b}}$ & $3.7(3.2)$ & $4.0(3.2)$ & $1.5(2.1)$ \\
\hline Minimum & 0 & 0 & 0 \\
\hline Median & 3.5 & 4 & 1 \\
\hline Maximum & 17 & 17 & 8 \\
\hline Upper limb rigidity ${ }^{c}$ & $1.0(1.3)$ & $1.1(1.3)$ & $0.4(0.7)$ \\
\hline Minimum & 0 & 0 & 0 \\
\hline Median & 0 & 0 & 0 \\
\hline Maximum & 5 & 5 & 3 \\
\hline Lower limb bradykinesia $^{c}$ & $0.7(1.1)$ & $0.8(1.2)$ & $0.3(0.6)$ \\
\hline Minimum & 0 & 0 & 0 \\
\hline Median & 0 & 0 & 0 \\
\hline Maximum & 6 & 6 & 2 \\
\hline Lower limb rigidity $^{c}$ & $1.0(1.4)$ & $1.1(1.4)$ & $0.3(0.7)$ \\
\hline Minimum & 0 & 0 & 0 \\
\hline Median & 0 & 0 & 0 \\
\hline Maximum & 6 & 6.0 & 2.5 \\
\hline Rest tremor ${ }^{d}$ & $0.04(0.3)$ & $0.1(0.3)$ & $0.0(0.0)$ \\
\hline Minimum & 0 & 0 & 0 \\
\hline Median & 0 & 0 & 0 \\
\hline Maximum & 3 & 3 & 0 \\
\hline Action tremor ${ }^{c}$ & $0.1(0.5)$ & $0.2(0.5)$ & $0.04(0.2)$ \\
\hline Minimum & 0 & 0 & 0 \\
\hline Median & 0 & 0 & 0 \\
\hline Maximum & 4 & 4 & 2 \\
\hline Axial signs ${ }^{e}$ & $1.9(2.4)$ & $2.0(2.4)$ & $1.2(1.9)$ \\
\hline Minimum & 0 & 0 & 0 \\
\hline Median & 1 & 2 & 1 \\
\hline Maximum & 24 & 24 & 13 \\
\hline
\end{tabular}

Abbreviations: Mn manganese; UPDRS3 Unified Parkinson Disease Rating Scale motor subsection part 3

a Poorer motor performance is indicated by greater UPDRS3 scores.

${ }^{\mathrm{b}}$ Sum of six UPDRS3 subscores: Finger-tapping, hand rotations, and rapid arm movements for each limb.

'Sum of the two UPDRS3 subscores (one for each limb).

${ }^{\mathrm{d}}$ Sum of five UPDDRS3 subscores: Upper limbs, lower limbs, and face.

e Sum of eight UPDRS3 subscores: Speech, facial expression, neck rigidity, difficulty arising from a chair, posture, gait, postural instability, and global bradykinesia. 
Table 4 Difference in motor outcomes associated with Mn exposure by community, Gauteng province, South Africa, 2016-2020

\begin{tabular}{|c|c|c|c|}
\hline & \multicolumn{3}{|c|}{$\begin{array}{l}\text { Mean difference between Mn smelter community vs. reference community in specified motor outcome } \\
(95 \% \mathrm{Cl})^{\mathrm{a}}\end{array}$} \\
\hline & Unadjusted & Age-adjusted & Fully-adjusted \\
\hline UPDRS3, total score ${ }^{b}$ & $5.6(4.1,7.1)$ & $6.6(5.2,7.9)$ & $6.3(4.9,7.7)$ \\
\hline \multicolumn{4}{|l|}{ UPDRS3 subscores ${ }^{\mathrm{b}}$} \\
\hline Upper limb bradykinesia ${ }^{c}$ & $2.5(1.8,3.1)$ & $2.9(2.2,3.5)$ & $2.9(2.2,3.6)$ \\
\hline Upper limb rigidity ${ }^{d}$ & $0.8(0.5,1.0)$ & $0.8(0.6,1.1)$ & $0.8(0.5,1.1)$ \\
\hline Lower limb bradykinesia $^{d}$ & $0.5(0.2,0.7)$ & $0.6(0.4,0.8)$ & $0.6(0.3,0.8)$ \\
\hline Lower limb rigidity ${ }^{d}$ & $0.8(0.6,1.1)$ & $0.9(0.6,1.2)$ & $0.9(0.6,1.2)$ \\
\hline Rest tremor ${ }^{\mathrm{e}}$ & $0.1(-0.01,0.1)$ & $0.1(-0.005,0.1)$ & $0.04(-0.02,0.1)$ \\
\hline Action tremor ${ }^{d}$ & $0.1(0.01,0.2)$ & $0.1(0.01,0.2)$ & $0.1(-0.02,0.2)$ \\
\hline Axial signs ${ }^{f}$ & $0.8(0.3,1.3)$ & $1.1(0.7,1.6)$ & $1.0(0.5,1.5)$ \\
\hline \multicolumn{4}{|c|}{ Grooved pegboard, time (seconds) } \\
\hline Dominant hand & $-7.6(-17.0,1.9)$ & $1.6(-7.2,10.5)$ & $0.9(-8.2,10.0)$ \\
\hline Non-dominant hand & $-4.0(-14.3,6.3)$ & $6.9(-2.6,16.3)$ & $7.5(-2.2,17.1)$ \\
\hline \multicolumn{4}{|c|}{ Kinematic testing, finger-tapping mean velocity (degrees/second) ${ }^{b}$} \\
\hline Dominant hand & $-68.4(-93.9,-43.0)$ & $-74.9(-101.2,-48.7)$ & $-69.0(-96.8,-41.3)$ \\
\hline Non-dominant hand & $-72.8(-99.6,-46.1)$ & $-82.6(-110.1,-55.2)$ & $-70.6(-99.6,-41.6)$ \\
\hline
\end{tabular}

Abbreviations: Mn manganese; UPDRS3 Unified Parkinson Disease Rating Scale motor subsection part 3

${ }^{a}$ Based on 716 participants (621 in Meyerton and 95 in Ethembalethu). Age adjustment was using age as a continuous variable with natural cubic splines with five knots (5th, 27.5th, 50th, 72.5th, and 95th percentiles) as per Harrell's placement method [35]. Fully adjusted means adjusted for age, sex, cigarette smoking (ever, former, current), and alcohol use (ever, former, current) (with all results confirmed in models with smoking as a dichotomous variable due to the small number of former smokers)

${ }^{\mathrm{b}}$ Poorer motor performance is indicated by greater UPDRS3 scores, greater grooved pegboard times, and lower finger-tapping velocities

c Sum of six UPDRS3 subscores: Finger-tapping, hand rotations, and rapid arm movements for each limb

d Sum of the two UPDRS3 subscores (one for each limb).

e Sum of five UPDRS3 subscores: Upper limbs, lower limbs, and face

${ }^{f}$ Sum of eight UPDRS3 subscores: Speech, facial expression, neck rigidity, difficulty arising from a chair, posture, gait, postural instability, and global bradykinesia

below that measured in the occupational study on which the current LOAEL for $\mathrm{PM}_{2.5}$-Mn is based [24].

Our study findings are consistent with several epidemiologic studies, using various methods, which demonstrate motor dysfunction in relation to environmental Mn exposure [16]. The study most similar to ours methodologically observed modest but significant differences in UPDRS3 in residents of Marietta, $\mathrm{OH}$, relative to a reference community, of 0.22 points [42]. While other prior studies used different methods of either assessing Mn or motor outcomes, our study adds to the literature by using a clinically valid and relevant quantitative measure of parkinsonism [25, 41]. One study in Canada demonstrated an association between computer-based tests of tremor, pointing, and pronation/supination hand movements and blood $\mathrm{Mn}[10,11]$. In a follow-up study of the Mn-exposed Ohio communities (Marietta and East Liverpool), investigators reported an association between Mn exposure and a computer-based tremor and finger-tapping performance (inverse) [14, 15]. Modeled $\mathrm{PM}_{2.5}-\mathrm{Mn}$ exposures ranged from 1 to $340 \mathrm{ng} / \mathrm{m}^{3}$. An Italian study of parkinsonism, defined by use of levodopa, found that municipalities with historic industrial $\mathrm{Mn}$ exposures and with higher soil concentrations of
Mn had higher standardized morbidity ratios for parkinsonism than other regions of Italy [12]. This same group investigated motor function, using the motor coordination tests in the Luria Nebraska Neuropsychological Battery, in residents from the same region of Italy, and found an association with $\mathrm{PM}_{10}-\mathrm{Mn}$, though the mean $\mathrm{PM}_{10}-\mathrm{Mn}$ was similar between the Mn-exposed and reference regions [13]. While these environmental studies provide consistent evidence of motor dysfunction in relation to even lower level Mn exposures than found in occupational settings, the pathophysiology of this motor dysfunction is largely unknown. Studies in occupational cohorts demonstrate evidence of a dose-dependent association between occupational $\mathrm{Mn}$-dose exposure and dopaminergic dysfunction $[19,20,43]$ and thalamic gamma aminobutyric acid (GABA) levels [8, 44]. The mechanism of this dysfunction may be due to $\mathrm{Mn}$ induced neuroinflammation $[45,46]$. Whether these same mechanisms apply to the much lower environmental exposures will require further study.

We focused on parkinsonism instead of PD, given the relatively low prevalence of PD.With that said, we did identify five participants with PD from our randomly sampled Meyerton population and no cases in 
Table 5 Grooved pegboard and kinematic motor outcomes, overall and by community, Gauteng province, South Africa, 2016-2020

\begin{tabular}{|c|c|c|c|}
\hline & $\begin{array}{l}\text { All participants } \\
N=716\end{array}$ & $\begin{array}{l}\text { Mn smelter community (Meyerton) } \\
N=621\end{array}$ & $\begin{array}{l}\text { Reference community } \\
\text { (Ethembalethu) } \\
N=95\end{array}$ \\
\hline & Mean (SD) & Mean (SD) & Mean (SD) \\
\hline \multicolumn{4}{|c|}{ Grooved pegboard test, time (seconds) $^{a}$} \\
\hline Dominant hand & $108.0(43.1)$ & $107.0(43.0)^{b}$ & $114.6(43.4)^{c}$ \\
\hline Minimum & 43.2 & 43.2 & 59.2 \\
\hline 25th percentile & 80.2 & 79.9 & 82.0 \\
\hline Median & 93.8 & 93.5 & 114.0 \\
\hline 75th percentile & 124.8 & 120.1 & 141.2 \\
\hline Maximum & 300.0 & 300.0 & 300.0 \\
\hline Non-dominant hand & $118.0(47.1)$ & $117.5(47.4)^{\mathrm{b}}$ & $121.4(44.8)^{c}$ \\
\hline Minimum & 51.4 & 51.4 & 60.0 \\
\hline 25th percentile & 86.9 & 87.1 & 85.1 \\
\hline Median & 103.8 & 103.2 & 114.7 \\
\hline 75th percentile & 131.7 & 130.3 & 150.3 \\
\hline Maximum & 300.0 & 300.0 & 241.1 \\
\hline \multicolumn{4}{|c|}{ Kinematic test - finger-tapping mean velocity (degrees/second) ${ }^{a}$} \\
\hline Dominant hand & $312.4(113.2)$ & $298.2(106.0)^{b}$ & $366.6(123.5)^{c}$ \\
\hline Minimum & 59.0 & 59.0 & 121.9 \\
\hline 25th percentile & 222.7 & 217.3 & 275.9 \\
\hline Median & 302.7 & 289.7 & 355.8 \\
\hline 75th percentile & 384.6 & 362.2 & 445.5 \\
\hline Maximum & 679.0 & 590.5 & 679.0 \\
\hline Non-dominant hand & $353.3(119.2)$ & $338.2(111.7)^{b}$ & $411.0(129.5)^{c}$ \\
\hline Minimum & 87.8 & 87.8 & 168.5 \\
\hline 25th percentile & 271.2 & 262.6 & 316.3 \\
\hline Median & 342.7 & 326.8 & 412.9 \\
\hline 75th percentile & 426.3 & 399.4 & 509.4 \\
\hline Maximum & 764.4 & 727.0 & 764.4 \\
\hline
\end{tabular}

Abbreviations: Mn manganese

a Poorer motor performance is indicated by greater grooved pegboard times and lower finger-tapping velocities

${ }^{b}$ Excludes 16 participants (grooved pegboard in dominant hand and non-dominant hand) and 275 participants (kinematic test in dominant and non-dominant hand) with missing data

' Excludes two participants (grooved pegboard in dominant and non-dominant hand) and four participants (kinematic test in dominant and non-dominant hand) with missing data

Ethembalethu, raising the possibility that PD may be relatively common in this community with high levels of inhalational $\mathrm{Mn}$ exposure relative to our reference region, in South Africa. However, our study was not powered to test that association, and any difference in PD prevalence might represent a chance finding. Nonetheless, our results are consistent with a previous study in which we used geographic information systems to investigate the geography of incident PD in the U.S. [18]. In that study, we used Medicare claims data to identify PD cases and calculated county-level PD incidence. We observed a higher incidence of neurologist-diagnosed PD in urban U.S. counties with high Mn release, compared with urban counties with none, which was specific to Mn emissions [18]. Using the 2005 EPA National-Scale Air Toxics Assessment (NATA), we estimated that the contemporary $\mathrm{Mn}$ exposures in these regions corresponded to approximately $0.00005-0.0008 \mathrm{mg} / \mathrm{m}^{3}$, levels substantially below the EPA LOAEL. The results of our previous geographic study are largely consistent with the estimates of environmental Mn exposure at which health effects may be seen, based upon the findings in this current study.

Our research participants reside in an environment of poverty and social neglect. The adult residents of these communities endure high rates of unemployment and 
many had very little education due to Apartheid era policies. The location of the Meyerton settlement near a source of industrial pollution is similar to the placement of low-cost housing in the U.S. and throughout the world. One unique aspect of our study is our success in recruiting a population of Black African residents in impoverished communities to investigate an environmental parkinsonism hypothesis. While we encountered many challenges, some unique to South Africa, when implementing this protocol, we were able to recruit successfully what is possibly the largest Black African parkinsonism cohort ever established. We anticipate future studies will continue to build on this success.

As with any study, there are some limitations. First, we only present mean community exposures. Ongoing efforts to model individual level inhalational Mn exposures from the smelter and other sources of airborne Mn should provide further insight into dose-response relations. Second, blinding the UPDRS3 to community of residence (Meyerton vs. Ethembalethu), i.e., Mn exposure status, was not possible, so we included additional motor assessments as an objective means to attempt to confirm the UPDRS3 results. These assessments, the accelerometry-based kinematic and GP tests, confirmed poorer motor performance among residents from Meyerton vs. Ethembalethu. Third, while overall recruitment was quite successful, not everyone invited to participate was willing to participate in the study, so there could be some bias toward those with or without symptoms participating in our study.However, we are not aware of incentives or disincentives for symptomatic or asymptomatic residents of Meyerton to participate and/or symptomatic or asymptomatic residents of Ethembalethu to not participate. Although we found that residents of both communities were overwhelmingly supportive of the research, we did not include anyone in the study who was not selected through the population-based sampling method. Fourth, this study focused on a specific Mn-exposed community; we do not know if these results are generalizable to other similar communities with environmental exposure to $\mathrm{Mn}$, even though the exposure levels overlap with those in some U.S. populations. Finally, we acknowledge that inter-individual variation in terms of actual Mn exposures and other factors that might affect $\mathrm{Mn}$ dose within the brain could be relevant to the motor outcomes of interest in this study.

We observed a strong relation between residential exposure to environmental $\mathrm{Mn}$ and parkinsonian motor signs at air concentrations substantially lower than international occupational thresholds. Although further detailed exposure quantification is ongoing, these results suggest that current U.S. and international Mn exposure limits may need to be revised.

\section{Conclusions}

In this large epidemiological study of environmental Mn exposure in South Africa, airborne Mn exposures at levels substantially lower than current occupational exposure thresholds in the U.S. may be associated with clinical parkinsonism.

\section{Abbreviations \\ ACGIH: American Conference of Governmental Industrial Hygienists; Cl: Confidence interval; EPA: Environmental Protection Agency; GABA: gamma aminobutyric acid; GP: Grooved pegboard.; km: Kilometers.; LOAEL: Lowest observed adverse effect level; Mn: Manganese; \\ NATA: National-Scale Air Toxics Assessment; PD: Parkinson disease; PM: Particulate matter; SD: Standard deviation; UPDRS3: Unified Parkinson Disease Rating Scale motor subsection part 3; U.S.: United States}

\section{Acknowledgements}

Not applicable.

\section{Authors' contributions}

BA Racette contributed to study conception and design, data acquisition, interpretation of data, drafting of the manuscript. G Nelson contributed to study conception and design, data acquisition, interpretation of data, substantial editing of the manuscript. WW Dlamini contributed to data acquisition, data analysis, interpretation of data, and substantial editing of the manuscript. P Prathibha contributed to data acquisition, interpretation of data, and substantial editing of the manuscript. J Turner contributed to data acquisition, interpretation of data, and substantial editing of the manuscript. M Ushe contributed to data acquisition, interpretation of data, and substantial editing of the manuscript. H Checkoway contributed to study design, interpretation of data, and substantial editing of the manuscript. L Sheppard study conception and design, data analysis, interpretation of data, substantial editing of the manuscript. S Searles Nielsen study conception and design, data analysis, interpretation of data, substantial editing of the manuscript. The author(s) read and approved the final manuscript.

\section{Funding}

The present work was supported by the $\mathrm{NIH}$ - National Institute of Environmental Health Sciences (NIEHS) (R01ES025991, R01ES025991-02S1, K24ES017765, K01ES028295). The funder played no role in the design or analysis of the study, or the decision to publish.

\section{Availability of data and materials}

Data from research participants in this study, who authorized sharing of their research data, will be made available to investigators with appropriate expertise and research support, after publication of the primary aims of this study. All shared data will be de-identified and will be released in accordance with U.S. and South African regulations.

\section{Declarations}

Ethics approval and consent to participate

The Washington University School of Medicine Human Research Protection Office (St. Louis, Missouri, U.S.) and the University of the Witwatersrand Human Research Ethics Committee (Johannesburg, Gauteng province, South Africa) approved this study (IRB ID \#201506129).All participants provided written informed consent.

\section{Consent for publication \\ Not applicable.}

\section{Competing interests}

B.A. Racette receives research support from the following government and non-governmental organizations: National Institute of Environmental Health Sciences (R01ES026891, R01ES026891-S1, R01ES025991, R01ES025991-02S1, R01ES030937-S1, R01ES029524), National Institute of Occupational Safety and Health (R01OH01 1661), Cure Alzheimer's Fund, Department of Defense (PD190057), Hope Center for Neurologic Disorders (Washington University). Dr. Racette has received honoraria (personal compensation) for lectures from 
the University of Michigan and Harvard University. He has received personal compensation for peer review from the Parkinson Study Group, service on the National Advisory Environmental Health Sciences Council for NIEHS, and legal testimony on behalf of the Johnson and Bell law firm. $\mathrm{G}$. Nelson receives research support from the following government organization: NIEHS (R01ES026891, R01ES026891-S1, R01ES025991, R01ES025991-02S1). She also receives personal compensation from journal "Occupational Health Southern Africa" for which she serves as editor. W. W. Dlamini declares no disclosures relevant to the manuscript. P. Prathibha declares no disclosures relevant to the manuscript. J.R. Turner receives research support from the following government and non-governmental organizations: NIH (R01ES025991, R01ES029846, R01HD098255, P42ES023716), UNICEF (GLA/2880/2019/002-PCA), and FHWA/ DOT (DTFH6117C00036). Dr. Turner has received personal compensation for service on the Science Advisory Board for EPA.

$\mathrm{M}$. Ushe receives research support from the following government organizations: NIEHS (R01ES025991) and NINDS (R01NS109487).

$\mathrm{H}$. Checkoway receives research support from the $\mathrm{NIOSH}(\mathrm{R01OH011661)}$ and NIEHS (R01ES025991). In 2020, he also received an honorarium for serving as a member of the Scientific Review Panel for University of Cincinnati Risk Science Center Assessment of the Carcinogenic Effects of Ethylene Oxide. $\mathrm{L}$. Sheppard receives research support from the following governmental and non-governmental organizations: NIEHS and NIA (R01ES026187), NIEHS (R25ES025503, R01ES026891, R01ES027696, R01ES026246, R01ES029509, R01ES029524), NIA (P01AG055367), Health Effects Institute. She has received personal compensation for service to the Environmental Protection Agency and the Health Effects Institute, and for peer review for The Lancet Planetary Health. She received small tokens of appreciation in lieu of travel to the Centre for Air Pollution, Energy, and Health Research in Australia. S. Searles Nielsen receives research support from the following governmental and non-governmental organizations: R01ES026891-03, K01ES028295-03, R01ES025991-05, R01ES025991-02S1, R01ES029524-02, Cure Alzheimer's Fund, Department of Defense (PD190057).

Statistical Analysis conducted by Susan Searles Nielsen and Wendy W. Dlamini at Washington University School of Medicine and Lianne Sheppard at the University of Washington.

\section{Author details}

${ }^{1}$ Department of Neurology, Washington University School of Medicine, 660 South Euclid Avenue, Campus Box 8111, 63110 St. Louis, Missouri, USA ${ }^{2}$ School of Public Health, Faculty of Health Sciences, University of the Witwatersrand, 7 York Road, 2193 Parktown, South Africa. ${ }^{3}$ Research Department of Infection \& Population Health, UCL Institute for Global Health, University College London, London, UK. ${ }^{4}$ Department of Energy, Environmental, and Chemical Engineering, Washington University, Campus Box 1180, One Brookings Drive, 63130 St. Louis, Missouri, USA. ${ }^{5}$ Department of Family Medicine \& Public Health, University of California, 9500 Gilman Drive, \# 0725, La Jolla, 92093-0725 San Diego, California, USA. 'Departments of Biostatistics and Environmental and Occupational Health Sciences, University of Washington, Box 357232, Washington, 98195 Seattle, USA.

\section{Received: 17 December 2020 Accepted: 3 March 2021}

\section{Published online: 15 March 2021}

\section{References}

1. Aschner M. Manganese: brain transport and emerging research needs. Environ Health Perspect. 2000;108(Suppl 3):429-32.

2. Nelson K, Golnick J, Korn T, Angle C. Manganese encephalopathy: utility of early magnetic resonance imaging. Br J Ind Med. 1993;50(6):510-3.

3. Chen P, Bornhorst J, Aschner M. Manganese metabolism in humans. Front Biosci (Landmark Ed). 2018;23:1655-79.

4. Roels H, Lauwerys R, Buchet JP, Genet P, Sarhan MJ, Hanotiau I, et al. Epidemiological survey among workers exposed to manganese: effects on lung, central nervous system, and some biological indices. Am J Ind Med. 1987;11(3):307-27.

5. Bouchard M, Mergler D, Baldwin M, Panisset M, Bowler R, Roels HA. Neurobehavioral functioning after cessation of manganese exposure: a follow-up after 14 years. Am J Ind Med. 2007:50(11):831-40.

6. Lee EY, Flynn MR, Lewis MM, Mailman RB, Huang X. Welding-related brain and functional changes in welders with chronic and low-level exposure. Neurotoxicology. 2018;64:50-9.
7. Racette BA, Searles Nielsen S, Criswell SR, Sheppard L, Seixas N, Warden MN, et al. Dose-dependent progression of parkinsonism in manganese-exposed welders. Neurology. 2017;88(4):344-51.

8. Ma RE, Ward EJ, Yeh CL, Snyder S, Long Z, Gokalp Yavuz F, et al. Thalamic GABA levels and occupational manganese neurotoxicity: Association with exposure levels and brain MRI. Neurotoxicology. 2018;64:30-42.

9. Bowler RM, Harris M, Gocheva V, Wilson K, Kim Y, Davis SI, et al. Anxiety affecting parkinsonian outcome and motor efficiency in adults of an Ohio community with environmental airborne manganese exposure. Int J Hyg Environ Health. 2012;215(3):393-405.

10. Mergler D, Baldwin M, Belanger S, Larribe F, Beuter A, Bowler R, et al. Manganese neurotoxicity, a continuum of dysfunction: results from a community based study. Neurotoxicology. 1999;20(2-3):327-42.

11. Baldwin M, Mergler D, Larribe F, Bélanger S, Tardif R, Bilodeau L, et al. Bioindicator and exposure data for a population based study of manganese. Neurotoxicology. 1999;20(2-3):343-53.

12. Lucchini RG, Albini E, Benedetti L, Borghesi S, Coccaglio R, Malara EC, et al. High prevalence of Parkinsonian disorders associated to manganese exposure in the vicinities of ferroalloy industries. Am J Ind Med. 2007;50(11): 788-800.

13. Lucchini RG, Guazzetti S, Zoni S, Benedetti C, Fedrighi C, Peli M, et al. Neurofunctional dopaminergic impairment in elderly after lifetime exposure to manganese. Neurotoxicology. 2014;45:309-17.

14. Bowler RM, Beseler CL, Gocheva W, Colledge M, Kornblith ES, Julian JR, et al. Environmental exposure to manganese in air: Associations with tremor and motor function. Sci Total Environ. 2016;541:646-54.

15. Kornblith ES, Casey SL, Lobdell DT, Colledge MA, Bowler RM. Environmental exposure to manganese in air: Tremor, motor and cognitive symptom profiles. Neurotoxicology. 2018;64:152-8.

16. Martin KV, Edmondson D, Cecil KM, Bezi C, Vance ML, McBride D, et al. Manganese Exposure and Neurologic Outcomes in Adult Populations. Neurol Clin. 2020;38(4):913-36.

17. Rentschler G, Covolo L, Haddad AA, Lucchini RG, Zoni S, Broberg K. ATP13A2 (PARK9) polymorphisms influence the neurotoxic effects of manganese. Neurotoxicology. 2012;33(4):697-702.

18. Willis AW, Evanoff BA, Lian M, Galarza A, Wegrzyn A, Schootman M, et al. Metal emissions and urban incident Parkinson disease: a community health study of Medicare beneficiaries by using geographic information systems. Am J Epidemiol. 2010;172(12):1357-63.

19. Criswell SR, Warden MN, Searles Nielsen S, Perlmutter JS, Moerlein SM, Sheppard $L$, et al. Selective D2 receptor PET in manganese-exposed workers. Neurology. 2018;91(11):e1022-e30.

20. Criswell SR, Nielsen SS, Warden MN, Perlmutter JS, Moerlein SM, Sheppard L, et al. [11 C]dihydrotetrabenazine Positron Emission Tomography in Manganese-Exposed Workers. J Occup Environ Med. 2020;62(10):788-94.

21. Criswell SR, Perlmutter JS, Videen TO, Moerlein SM, Flores HP, Birke AM, et al. Reduced uptake of [18F]FDOPA PET in asymptomatic welders with occupational manganese exposure. Neurology. 2011;76(15):1296-301.

22. Meyer-Baron M, Knapp G, Schaper M, van Thriel C. Performance alterations associated with occupational exposure to manganese-a meta-analysis. Neurotoxicology. 2009;30(4):487-96.

23. American Conference of Governmental Industrial Hygienists (ACGIH). TLVs and BEls. Cincinnati, Ohio: ACGIH; 2020. Report No.: Product ID 0120.

24. Roels HA, Ghyselen P, Buchet JP, Ceulemans E, Lauwerys RR. Assessment of the permissible exposure level to manganese in workers exposed to manganese dioxide dust. $\mathrm{Br} J$ Ind Med. 1992;49(1):25-34.

25. Fahn S, Elton RL, Members of the UPDRS Development Committee. Unified Parkinson's disease rating scale. In: Fahn S, Marsden CD, Goldstein M, Calne DB, editors. Recent developments in Parkinson's disease. New York: Macmillan; 1987. pp. 153-63.

26. Lafayette Instrument Company. Grooved Pegboard Test User Instructions. Lafayette Instrument Company. Lafayette: Lafayette Instrument Company; 2002.

27. Giuffrida JP, Riley DE, Maddux BN, Heldman DA. Clinically deployable Kinesia technology for automated tremor assessment. Mov Disord. 2009;24(5):723-30.

28. Pulliam CL, Heldman DA, Orcutt TH, Mera TO, Giuffrida JP, Vitek JL. Motion sensor strategies for automated optimization of deep brain stimulation in Parkinson's disease. Parkinsonism Relat Disord. 2015;21(4):378-82.

29. Espay AJ, Giuffrida JP, Chen R, Payne M, Mazzella F, Dunn E, et al. Differential response of speed, amplitude, and rhythm to dopaminergic medications in Parkinson's disease. Mov Disord. 2011;26(14):2504-8. 
30. Heldman DA, Espay AJ, LeWitt PA, Giuffrida JP. Clinician versus machine: reliability and responsiveness of motor endpoints in Parkinson's disease. Parkinsonism Relat Disord. 2014;20(6):590-5.

31. Heldman DA, Giuffrida JP, Chen R, Payne M, Mazzella F, Duker AP, et al. The modified bradykinesia rating scale for Parkinson's disease: reliability and comparison with kinematic measures. Mov Disord. 2011;26(10):1859-63.

32. StataCorp. Stata MP 14.2. MC 14.2 ed. College Station: StataCorp LP; 2015.

33. Kulkarni P, Chellam S, Flanagan JB, Jayanty RK. Microwave digestion-ICP-MS for elemental analysis in ambient airborne fine particulate matter: rare earth elements and validation using a filter borne fine particle certified reference material. Anal Chim Acta. 2007:599(2):170-6.

34. Occupational Safety and Health Administration (OSHA). TABLE Z-1 Limits for Air Contaminants, United States Department of Labor. Code of Federal Regulations Title 29, Part 19101000, Table Z-1. Government Publishing Office. 2011. p. 7-14

35. Harrell FE. General Aspects of Fitting Regression Models. Regression Modeling Strategies: With Applications to Linear Models, Logistic and Ordinal Regression, and Survival Analysis. Cham: Springer International Publishing; 2015. pp. 13-44.

36. Stone CJ. [Generalized Additive Models]: Comment. Statistical Science. 1986; 1(3):312-4.

37. Hernan MA, Takkouche B, Caamano-Isorna F, Gestal-Otero JJ. A metaanalysis of coffee drinking, cigarette smoking, and the risk of Parkinson's disease. Ann Neurol. 2002;52(3):276-84.

38. Zhang $\mathrm{D}$, Jiang $\mathrm{H}$, Xie J. Alcohol intake and risk of Parkinson's disease: a meta-analysis of observational studies. Mov Disord. 2014;29(6):819-22.

39. Ritz B, Ascherio A, Checkoway H, Marder KS, Nelson LM, Rocca WA, et al. Pooled analysis of tobacco use and risk of Parkinson disease. Arch Neurol. 2007;64(7):990-7.

40. Nelson G, Ndlovu N, Christofides N, Hlungwani TM, Faust I, Racette BA. Validation of Parkinson's Disease-related Questionnaires in South Africa. Parkinsons Dis. 2020;2020:7542138.

41. Dlamini WW, Nelson G, Nielsen SS, Racette BA. Manganese exposure, parkinsonian signs, and quality of life in South African mine workers. Am J Ind Med. 2020;63(1):36-43.

42. Kim Y, Bowler RM, Abdelouahab N, Harris M, Gocheva V, Roels HA. Motor function in adults of an Ohio community with environmental manganese exposure. Neurotoxicology. 2011;32(5):606-14.

43. Criswell SR, Nielsen SS, Warden M, Perlmutter JS, Moerlein SM, Flores HP, et al. [(18)F]FDOPA positron emission tomography in manganese-exposed workers. Neurotoxicology. 2018;64:43-9.

44. Dydak $\mathrm{U}$, Jiang YM, Long LL, Zhu H, Chen J, Li WM, et al. In vivo measurement of brain GABA concentrations by magnetic resonance spectroscopy in smelters occupationally exposed to manganese. Environ Health Perspect. 2011;119(2):219-24.

45. Gonzalez-Cuyar LF, Nelson G, Criswell SR, Ho P, Lonzanida JA, Checkoway H, et al. Quantitative neuropathology associated with chronic manganese exposure in South African mine workers. Neurotoxicology. 2014:45:260-6.

46. Santos D, Batoréu MC, Tavares de Almeida I, Davis Randall L, Mateus ML, Andrade $\mathrm{V}$, et al. Evaluation of neurobehavioral and neuroinflammatory end-points in the post-exposure period in rats sub-acutely exposed to manganese. Toxicology. 2013;314(1):95-9.

\section{Publisher's Note}

Springer Nature remains neutral with regard to jurisdictional claims in published maps and institutional affiliations.

Ready to submit your research? Choose BMC and benefit from:

- fast, convenient online submission

- thorough peer review by experienced researchers in your field

- rapid publication on acceptance

- support for research data, including large and complex data types

- gold Open Access which fosters wider collaboration and increased citations

- maximum visibility for your research: over $100 \mathrm{M}$ website views per year

At BMC, research is always in progress.

Learn more biomedcentral.com/submissions 